\title{
THE INVESTIGATION OF LITERARY AND MUSIC FROM THE ONTOLOGY PERSPECTIVE IN ACCORDING TO THE INGARDEN'S VIEW
}

\begin{abstract}
The classical music works have a single ontology. On the one hand, the musical work is the one that the composer has composed, and on the other hand, this work gets a different existence every time. The existence of literary work is also a layer of layer, and the effect is realized in varying degrees in each of these layers. Roman Ingannd is the founder of the ontology of art. According to Ingardin's view, every work of art has unconventional spaces that the audience completes during their aesthetic experience. Therefore, understanding the work of art requires the active participation of the audience and the work is calibrated in an interdisciplinary approach.
\end{abstract}

Keywords: Ontology, phenomenology, music, literary work, Ingarden.

\section{Introduction}

\section{Ali Ashrafi ${ }^{1}$}

Roman Innard is the father of phenomenological aesthetics. His works included the ontology, logic, and the theory of literature, the recognition of the work of literary art and ontology of the work of art, musical work, image, architecture and film. Inghardin have considered the works of art and believed that these works belong to the realm of reality, and they are not ideally suited to his belief that artworks are objects that are not completely self-contained and are dependent on the intentional intentional actions of their creators and their audience, and subsequently they are considered a tangible object.Therefore, in his numerous works, he shows that the art works is not proportional to realism or ideality, and the subject of aesthetic research is in fact an interstitial of artistic objects. These actions are embodied in artistic or other material manifestations and re-live in the audience's awareness. In particular, the literary works are a
\end{abstract}

\footnotetext{
${ }^{1}$ Department of English language, University of Applied Science and Technology, Tehran, Iran. Email: Ali.Ashrafi.Sarvak11@gmail.com
} 
wide-ranging field for the transition of ideology to ontology. That is the meaning that the effect is neither autonomous and is not entirely based on the author's and audience's knowledge, but is based on the paradox of both of them and goes beyond them. In addition, material object and the art work is distinguishable both from what the objectification of the aesthetic object calls. Therefore, the determined artistic work is the real aesthetic object. For a better understanding of the integral aesthetics of the two, we have come up with two schemes. The first plot shows how to put his discussions under three categories. Indeed, his intellectual efforts can be subdivided into three subjective, objective and interdisciplinary poles. Ingharden was never bound to aesthetic subjectivity. The second plot represents the unique achievement of Ingardon in discussing the ontological nature of the work of art. The work of art is something like everything else, and it does not differ in other words from the other. The characteristic feature of the work of art is its intention, that is, it originates from creator conscious actions and is linked with the actions of the audience's awareness; So the artwork is an intentional object. The artistic work is then transformed into an aesthetic object whose structure is determined. In other words, the cycle of aesthetic perception cannot be complete unless the audience determines the schematic spaces of the uncertain spaces. In fact, Ingarden expanded the idea of obtaining the work of art, and determination as a characteristic feature of this theory. It should be noted that this approach has had a dramatic effect on Hans-Robert Yas and Vasf-Gang aiser. Also, the role of the audience in assigning a work of art to a collaborative understanding with Rudolf Bultman is also comparable. The discussion of the contribution of the interdisubject to the work of art mainly concerns the discussion of aesthetic values. $\mathrm{He}$ also showed that the evaluation and interpretation of the artistic work depends on the objective structure of various artistic forms. Therefore, the value of the effect can not only be extracted from the subjective conditions of the audience. From this point of view, his thoughts are closely related to aesthetic factualism. In fact, Ingarden believes that any aesthetic perception is necessarily based on the schematic structure of the artistic work. In other words, the pillars and passive 
elements of this structure (poles) objective (which provides the aesthetic potential of the subjective pole). So, according to the phenomenological interpretation, the aesthetic pleasures of a grateful aesthetic object. In this paper, the ontology of music and literature is discussed from the perspective of Inghard.

\section{Ontology of musical effect}

We should consider the place of a pure "pure intention" for the musical work. The fact that the musical act as an appealing partner is a schematic. And it is possible to realize in various forms, is a confirmation of this position. Then concludes, real things exist in their own way and they have characteristics that are completely independent of how we understand the human beings we associate with them in the practical life directly. Then, by virtue of intentional action, whether there is creative composer action or party guidance instructions. In this way, musical traces exist in an alternate way and, depending on their characteristics, depend on the final analysis of the intersubjective meanings that gradually form the effect. Once this concept has been gradually

\section{6}

formed, it is recognized among the people of the world, and the way specifies how music is played. Nonetheless, the prevailing musicians have the ability to do it the very way Establish a new one and open up new ways, and as a result, bring the audience with music and listening. Accompany them. In this way, a musical instrument is created interdisciplinary. Ingrden distinguishes between music and its performances in the ontological study of music, and they make them two distinct facets. The most distinctive feature of the musical effect and its implementation is that the implementation arrives at the time of objective and objective beginnings and starts and ends. Therefore, each performance is unique in its nature and different from other performances. In addition, musical performances have an audio effect and is the result of musicians' actions on instruments. Performing music objectively and phenomenally in a specific place in such a way that the listener will hear the different balances of the sounds by changing the location at the place of play. Hearing perceptual music is continuous and seamless, therefore, with changes in the attention and focus of the 
audience, his musical perception is also changing. The ontological features of the musical (partisan) effect make it possible to distinguish it from its performances. Inghardon explains that the musical effect is endemic and time-consuming, that is, after the composition is staggered and places different times and cultures, while live performances do not exist after the end (unless the case recorded it). Therefore, the musical effect is a continuous entity. But although the musical effect is not ideal (that is, in real time and in real place, it cannot be considered an actual entity since, for example, its various parts are synchronous and non-sequential and independent. Each musical piece is a single entity; that is, from the Brahms one of the first symphonies there is only one original party, while its performances are multiplied. The musical effect will not be determined until it is implemented. Composers sometimes cast many performances into musicians and merely refer to ghosts like spiky, slow, long, and so on, and they interpret it to the musician. The fact that is the nature of the musical work will never be completely and completely unidentified. First, technological developments and the acoustic advancements of the continuously functioning locations transform Ozia's effect. For example, we do not know if Chopin had access to contemporary pianos, he would make a difference in his work. In other words, the idealization of a musical piece is always out of reach, and thus its aesthetic ideals will never be realized. Especially in orchestral music, aesthetic perfection is virtually unattainable, because it is always possible for diverse musicians and instrumentalists to express their technical and audio specification.

The time and the presence of outstanding artists always affect the performance of musical works. For example, at the beginning of the 20th century, under the influence of the neuromatic climate, Chopin's works were performed with a passionate emotional passion. The absolute musical authority of Herbert Fan-Karaan as the most celebrated leader of the twentieth century orchestra and the most powerful figure in classical music has made his performances a spectacle of musical quality, while Karayan followed a distinct and distinctive personal approach, They did not agree on it.

\section{Ontology of literary work}


In the art of literary art, Ingarden begins his discussion with the question of how literary work is. In other words, should literary work be the real nature or ideals? If we consider Goethe's Faust, we find that this effect has been created in a specific time and place. It is always possible for the author or the publisher to make changes in the course of the work, to shorten or recall parts, to understand other parts, change the words, and scrape the seasons and so on. But Faust is a sequence of sentences, and it is therefore an idealistic object. The point is that literary work, in contrast to ideal ideals, such as five, triangular, red, white, and so on, really exists and is tangible and objective. Inghardon shows that literary work is neither a psychological nature nor an imaginary entity. On the other hand, it is necessary to distinguish between the author and the effect. Although the work, result, the author's experiences, and world view of emotions and emotions are in a certain style, the author and his work are disparate objects. In other words, the literary work in terms of an ethics is an autonomous object. Ingardin picks up a rainbow and says that the rainbow is out of a divergent subject, but in terms of Antic has no independent existence, that is, one can not define the properties of an independent object (table and tree, and Cat and the like) to the rainbow. Literary work also has such a characteristic. Whether or not it is: The book is on the germinal table, and Emile Zola wrote it in 1885 and published thousands of copies in various languages. But if we ask, is Etine Lanthia, the hero of the novel, where is now and what? Inevitably, we must say that neither he nor the other characters and events of the novel have external existence. The ontology of the aesthetic object leads to layering theory, according to which the literary work is a layered pattern. The combination of these layers, which ultimately leads to the creation of multitonal harmony of literary work. In addition, each of these layers has different aesthetic qualities. Ingardon considers the four-dimensional literary work. These layers are as follows: Vocabulary, Vocabulary, Schematic, and Representative Objectives. Every literary work is composed of "Vocabulary sequencing (written or written) in such a way that this layer for the experience and calendar of the literary work is essential. The reader understands the meaning of these words and is based on the necessity of 
recreating the world and the objects described in the author's style and style in his mind and spirit. For example, the film's adaptation uses a literary work of this four-dimensional layout and represents the image. These four layers are evident in how the vocabulary is structured (first layer), the way in which the concepts and themes are created (second layer), the description and drawing of the characters and scenes and events (third layer), and the plotting of the plot and the narrative (fourth layer). Also, Ingarden points out that these layers come to an organic unity in a literary work and merge into each other. What is usually called the sensation or the effect of the effect is rooted in the third layer, which means that when we call tragic, humorous, profound, and sensitive and so forth, we actually refer to the features of the third layer. Ingharden calls these features metaphysical qualities of literary work.

\section{Conclusion}

The ontology of music and literary work is one of the most important achievements of Ingarden for the aesthetics of the twentieth century, which has also influenced contemporary analytical ontology. In according to the Ingarden 's perspective that the classical musical work has a lot of existential modes, that is, the party and its performances each consolidates the aspect of the ontology of music. According to this feature, the ideal musical effect is unattainable because each performer has unique features that are not necessarily seen in other performances. The ontology of literary work is also the layer of the layer, and the literary work of consistency of combining and integrating these different layers is conserved. Artwork in general has unconventional spaces that are completed only with the participation of the audience. Indeed, non-native works of artistic work are identified through the process of reading, and this process is the product of intentional tensile consciousness.

\section{References}

Gniazdowski, Andrzej. (2010). "Roman Ingarden", Handbook of Phenomenological Aesthetics, eds. Hans Rainer Sepp, L. Embree, Dordrecht: Springer. 
Ingarden, Roman. (1973a). The Literary

Work of Art. An Investigation on the Borderlines of Ontology, Logic, and Theory of Literature, translated by George G. Grabowicz, Evanston, Illinois: Northwestern University Press.

Ingarden, Roman. (1973b). The Cognition of the Literary Work of Art, translated by Ruth Ann Crowley and Kenneth R. Olson, Evanston, Illinois: Northwestern University Press.

Ingarden, Roman. (1989). Ontology of the Work of Art. The Musical Work, The Picture, The Architectural Wrok, The Film, translated by Raymond Meyer with John T. Goldthwait, Athens, Ohio: Ohio University Press.

Iseminger, Gary. (1973). «Roman Ingarden and the Aesthetic Object», Philosophy and Phenomenological Research, Vol. 33, No. 3, pp. 417-420.

Limido-Heulot, Patricia. (2013). Roman Ingarden, Rennes: Presses universitaires de Rennes.

Mitscherling, Jeff. (1997). Roman Ingarden's Ontology and Aesthetics, Ottawa: University of Ottawa Press.
30

Potocki, Christophe. (2013). «Introduction», Roman Ingarden : ontologie, esthétique, fiction, sld. J.-M. Schaeffer, Paris: Editions des archives contemporaines 